informed that the smell of American pennyroyal (Hedeoma pulegioides), when sufficiently strong, drives them away at once. A few drops of the essential oil extracted from this plant added to an ointment and rubbed upon the skin will secure relief from these pests; likewise a sleeping apartment may be freed from them by strewing about a quantity of the leaves of the plant; or by allowing a quantity of the essential oil to evaporate in it. European pennyroyal (Mentha pulegium) is said to be very similar, and might possibly have the same effect.

Lyons, New York, August 30

M. A. VEEDER

\section{Hardening of Steel}

In NATURE, vol. xxii. p. 220, Mr. H. T. Johnston-Laris supposes the absorption of hydrogen to be necessary for steel to get hard.

The following facts seem to prove that this absorption can be very well dispensed with in hardening :-

I. Small pieces of steel wire can be hardened by moving them swiftly through the air when red hot, or by pressing them against a piece of cold metal.

2. Steel can be hardened very well by cooling in quicksilver. Both facts seem to state that only rapid cooling is wanted for steel to get hard.

Dordrecht, iSeptember 8

T. W. GiLTAY

\section{THE NEW ZEALAND INSTITUTE}

PROBABLY none of our colonies have done so much for the promotion of the higher interests of their people as New Zealand; in this respect, indeed, it will compare favourably with almost any other country in the world. Its university is wonderfully complete and well organised; all the faculties are well represented ; science, as well as literature, has its right place in the curriculum; the best men are tempted to go out as professors from the old country; and laboratory research is fairly encouraged. Quite recently we referred to a proposed system of education, which in its comprehensiveness and completeness will hold its own with any national system of education in Europe. The New Zealand Institute, again, is probably one of the best organised, and for its purpose, among the most efficient scientific bodies to be found anywhere. It is virtually a Government institution, and was organised by a special Act in 1867 . It seems to bear the same relation to its incorporated societies that a university does to its affiliated colleges; it is independent of these societies, which must comply with certain rules imposed upon them by the Institute, and yet without these societies its occupation would seem to be gone. One part of its duty is the publication of summaries of the Proceedings of the societies, and of such papers and records in full as the Institute may deem of permanent scientific value. The societies at present incorporated with the Institute are the Wellington Philosophical Society, the Auckland Institute, the Philosophical Institute of Canterbury, the Otago Institute, the Westland Institute, and the Hawkes Bay Philosophical Institute. It must be gratifying in the highest degree to those who have the best interests of New Zealand at heart to find a love for culture so widespread as the existence of these societies indicate. And it must be remembered that, as a condition of incorporation with the Institute, each society must come up to a certain standard of membership and contribute a considerable sum yearly to the promotion of science, art, and literature, which is the aim of the Institute.

The genuine good work which the Institute is doing, and its efficiency in promoting not only science, but through that the practical interests of the colony, is evident from the handsome volume of Transactions which it publishes yearly, and which are entitled to take their place among the best class of similar publications. Some idea of the work which the Institute is doing, and of the value of its Transactions, may be obtained from the two last volumes, for 1878 and 1879 , which we have just received.

Of course the first aim of a society like this, in a fresh country like New Zealand, should be the working ont of its natural history (in its widest sense) in a scientific method. This the Institute has done and is doing, and its publications, and the publications of the separate societies, are already a mine of information on all subjects connected with New Zealand. The volumes before us contain a large number of papers on zoology, botany, chemistry, and geology, all of them important contributions to these various departments of science. Prof. Hutton, whose name is well known in this country, contributes a number of valuable papers on the various divisions of the fauna of New Zealand. Prof. von Haast (another name well known to science) has other various contributions of special value, and Mr. T. W. Kirk, of the Colonial Museum, has a long list of papers both on zoology and botany, all of them of novelty and interest, and several of them on such practically important subjects as Grasses and Fodder Plants. Other able workers in these departments are Mr. $D$. Petrie, Mr. W. Colenso, Mr. Charles Knight, Mr. Buchanan, and Mr. Buller. From Mr. J. C. Craufurd and Mr. W. Collie we have valuable contributions relating to the geology of New Zealand. Several of the papers classed under the head of Miscellaneous are of the greatest importance and interest. Thus we have papers of immense practical value to the colony on the Forest Question in New Zealand, by Mr. A. Lecoy; on the Influence of Forests on Climate and Rainfall, by Mr. F. S. Peppercorne; and on Forest Planting and Conservation, by Mr. G. W. Wilkins. Equally important from a colonial as well as a scientific standpoint is Commander Edwin's paper on the Principle of New Zealand Weather Forecast. We have several excellent papers on the New Zealand natives of much ethnological value : "Notes on Port Nicholson and the Natives in 1839," by Major Heaphy; "On the Ignorance of the Ancient New Zealander of the Use of Projectile Weapons," by Mr. Coleman Phillips; "Contributions towards a Better Knowledge of the Maori Race," by Mr. W. Colenso; "Notes on an Ancient Manufactory of Stone Implements," by Prof. von Haast, F.R.S. ; and "Notes on the Colour-Sense of the Maori," by Mr. J. W. Stack. Mr. W. Colenso contributes papers on the Moa, a subject of great scientific interest. Mr. J. H. Pope's "Notes on the Southern Stars and other Celestial Objects" is a valuable contribution to astronomy. Prof. Bickerton has several papers on subjects of wide scientific interest,-on "Partial Impact," the "Genesis of Worlds and Systems," the "Birth of Nebulæ" ; while Prof. F. W. Frankland writes interestingly on "The Doctrine of Mind-Stuff." There are several good chemical papers by Mr. W. Skey. In the Proceedings of the several societies there are numerous shorter papers of varied interest, as on Moa Feathers, by Dr. Hector ; on Musical Tones in the Notes of Australian Birds, by Mr. C. W. Adams; on a new fish, by Prof. Hutton; and many others on subjects of wide and varied interest. We have besides meteorological, earthquake, and other records, and a variety of miscellaneous matter, all of real importance.

An institution capable of producing so much valuable work year after year deserves every encouragement from the government of the country. The New Zealand Government has hitherto granted a subsidy of $500 \%$. yearly to the Institute, just sufficient, we believe, to defray the expenses of printing the Transactions, which are freely distributed to other societies all over the world. We are therefore astounded to learn that the Government has decided to withdraw this grant, thus suddenly bringing these valuable Transactions to a standstill. We can scarcely credit the statement; it is difficult to believe that so enlightened a Government as that of New Zealand 